\title{
Application of Spaghetti Diagram in Layout Evaluation Process: A Case Study
}

\author{
Naqib Daneshjo ${ }^{1}$, Vladimír Rudy ${ }^{2}$, Peter Malega ${ }^{2}$, Paulína Krnáčová ${ }^{1}$ \\ ${ }^{1}$ University of Economics in Bratislava, Faculty of Commerce, Dolonozemská cesta 1, \\ 85235 Bratislava 5, Slovak Republic \\ ${ }^{2}$ Technical university of Kosice, Faculty of Mechanical Engineering, Letná 9, 04200 Košice, Slovak Republic
}

\begin{abstract}
The case study of the Spaghetti diagram application in the evaluation of the production workplace layout was carried out in order to verify the proposed Excel application in specific production conditions. This paper presents an analysis of the existing workplace layout and two new proposals of layout. The analysis was realized for all layouts using Excel application Spaghetti diagram and the obtained results were compared with each other. In conclusion, the experience with Excel application was summarized and advantages and disadvantages of its use were specified. The defined approach also expects the usage of other methods and tools, such as video-based time analysis tools. In a comprehensive approach to layout issue, the paper specifies the possibility of an effective combination of different methods and tools and sets out directions for further development.
\end{abstract}

Keywords - production system, layout, spaghetti diagram, Excel application, workplace.

\section{Introduction}

The issue of layout is not only related to the process of designing a new production area solution, but has also importance in the existing production process.

DOI: $10.18421 /$ TEM102-12

https://doi.org/10.18421/TEM102-12

Corresponding author: Daneshjo Naqib ,

Faculty of Commerce of the University of Economics in

Bratislava, 85235 Bratislava 5, Slovak Republic.

Email: daneshj047@gmail.com

Received: 03 March 2021.

Revised: 22 April 2021.

Accepted: 05 May 2021.

Published: 27 May 2021.

(c) BY-NC-ND (C) 2021 Daneshjo Naqib et al; published by UIKTEN. This work is licensed under the Creative Commons Attribution-NonCommercial-NoDerivs 4.0 License.

The article is published with Open Access at www.temjournal.com
There are a number of reasons for the necessity to review the existing layout of the production area and propose changes. Such a task may be related to the necessity for space saving, the effort to reduce the workload, the necessity to improve the work organization, and the necessity to realize production changes that require, for example, the usage of a new pallet type, different way to handling or transport realization [1], [4]. In existing production, rearrangements are always complicated, because there are a number of constraints. These conditions relate, for example, to the necessity to retain some technical equipment in its original location, to maintain free paths for the movement of workers or handling equipment, the impossibility to change the workflow, and etc. [3]. All changes proposed have to comply with safety regulations. For many existing plants, the 3D model may not be available, or the documentation is processed in a program that is not easily compatible with the currently used CAx systems that allow solving and evaluating layout changes. For this reason, it is necessary to choose a different approach that will allow evaluating layout changes quickly and efficiently [14]. Spaghetti diagram can be used for evaluation of layout changes of smaller production areas.

\section{Excel Application of Spaghetti Diagram}

An Excel application was created to use the Spaghetti diagram as a tool for displaying the movement of an object in the monitored system in the form of a line [15]. This Excel application allows the user to evaluate the movement in terms of time, distance and number of work positions and to compare the proposed variants of layout, respectively proposed layout changes [2]. The layout evaluation procedure using Excel application is shown in Figure 1. The first step of this procedure is the analysis of the problem situation and set the goal of the analysis. In this step, it is necessary to define the basic problem; respectively problems in which the worker does not manage to operate the equipment, complicated time-consuming movement of the worker, and etc.

In setting the goal, it is also necessary to define objective facts that cannot be changed, such as the location of the equipment, the way of handling with the pallets, and etc. 


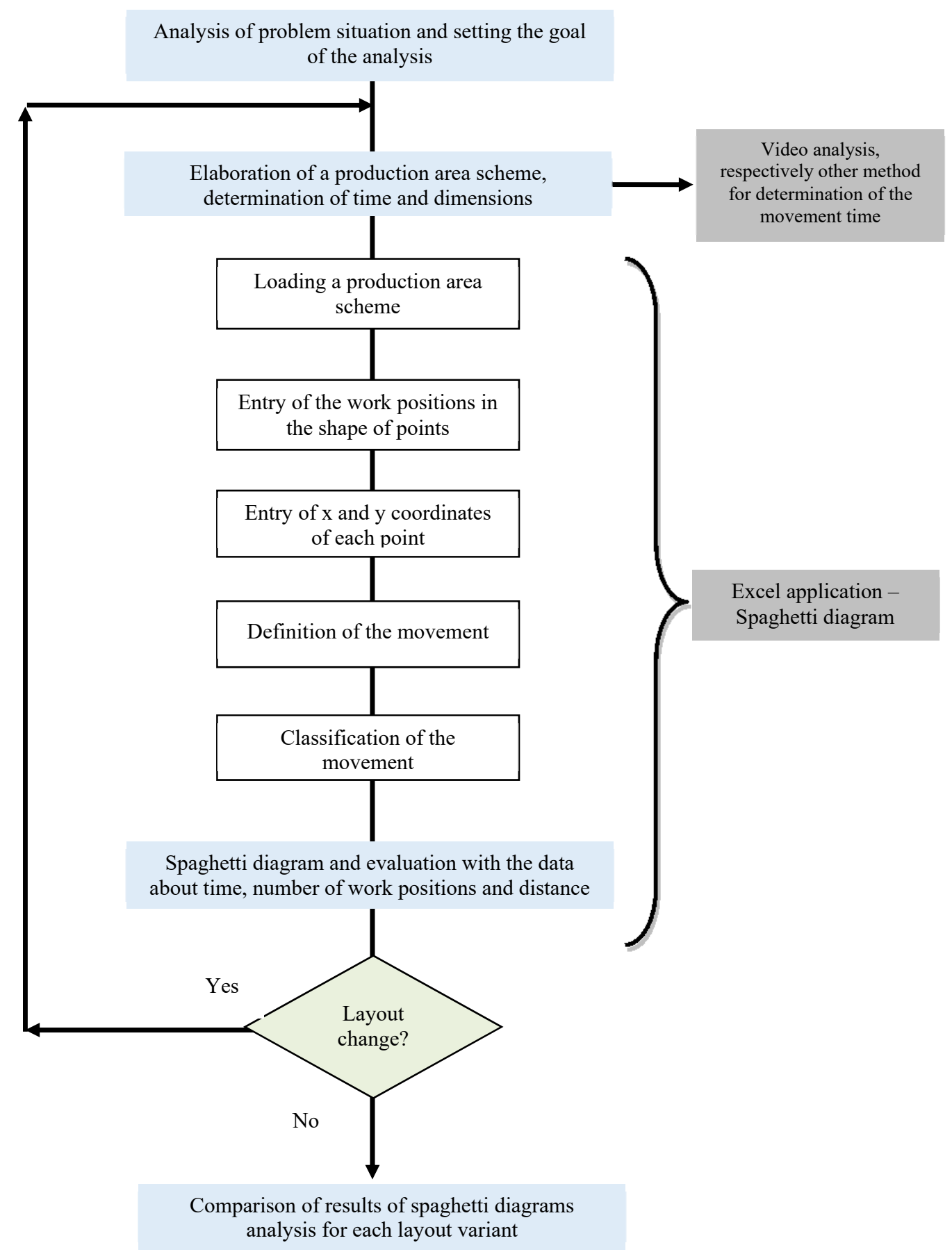

Figure 1. Procedure of layout evaluation using Excel application - Spaghetti diagram

If it follows from the above analysis that it is necessary to change the arrangement of equipment in the workplace within the given limits, it is possible to go to the next step, namely to elaborate the layout scheme of the workplace equipment or to verify if the existing schema or 3D model corresponds to reality. Exact dimensional data should also be available in this scheme or model [5]. The next step is the specification of the process of equipment operation, respectively work area activities. It is about determining the type of activities and their sequence [13]. This is followed by the classification of activities according to the established classification system and the allocation of time for each activity. Time determination can be performed by calculation, direct measurement in production system, or according to video analysis. The documents prepared in this way serve as the basis for the development of the Spaghetti diagram using an existing Excel application. To evaluate the layout, the first application of the Spaghetti diagram relates to the existing layout [12]. Obtained results are used for comparison with the newly designed layout variant or variants.

All further steps are already performed in Excel application. The steps of this procedure were 
published in detail in [10]. The results of the analyses, i.e. the evaluation of each layout needs to be compared and together with other criteria, such as the cost of implementation, serve to decide about the selection of layout variant.

\section{Analysis of Existing Production System}

The analysed workplace that is shown in Figure 2 is concerned with the production of door panels (Figure 4) and armrests (Figure 5). It is a grouping of two pre-heating and forming press production equipment, 2 workbenches, 2 trolleys and 13 containers for semi-finished products, finished products and waste. The first activity is to load the semi-finished products on the trolley 1 and 2 for a total of 50 loads into the heating press and press. A set of semi-finished products is shown in Figure 3. Four products are made from each set -2 door panels and 2 armrests.

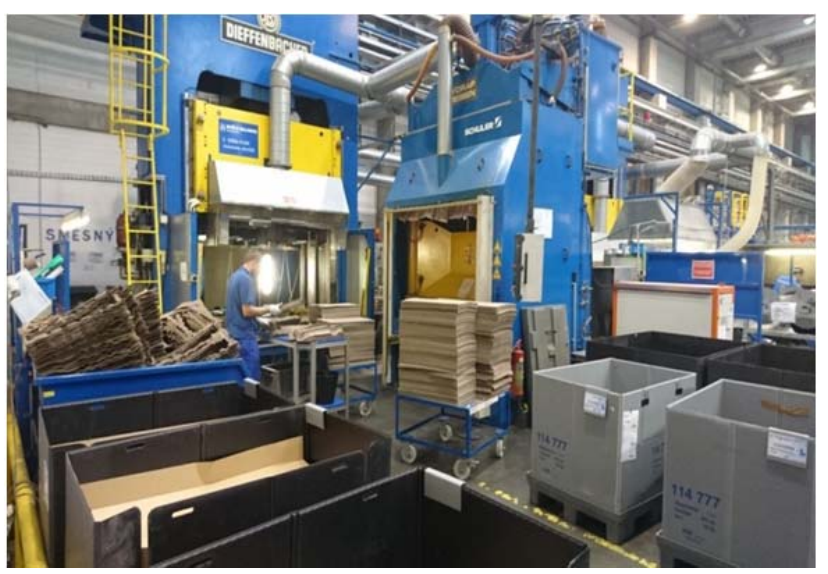

Figure 2. Existing workplace

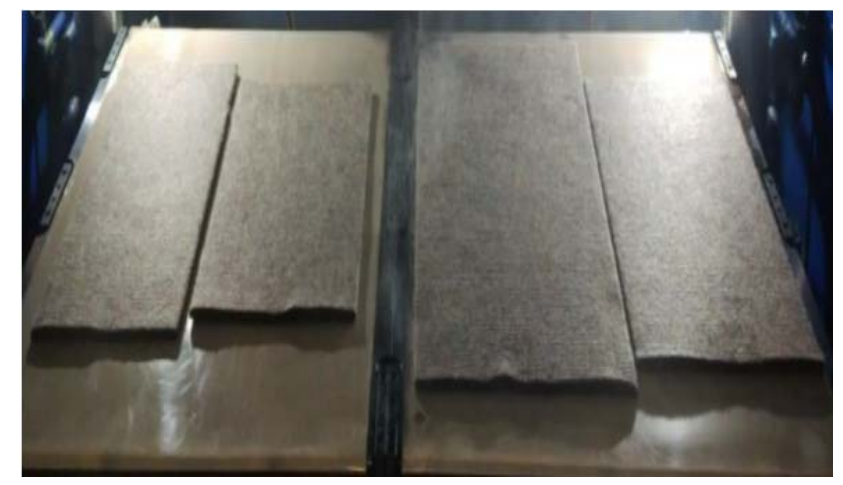

Figure 3. Example of semi-finished product

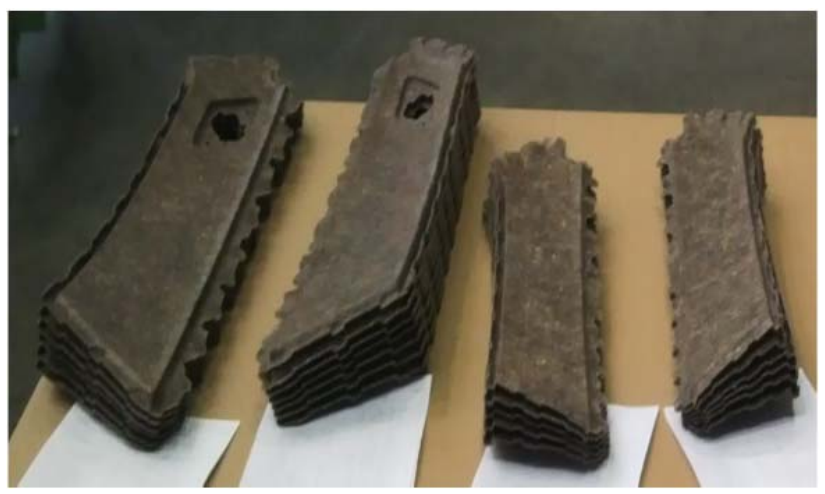

Figure 4. Door panel

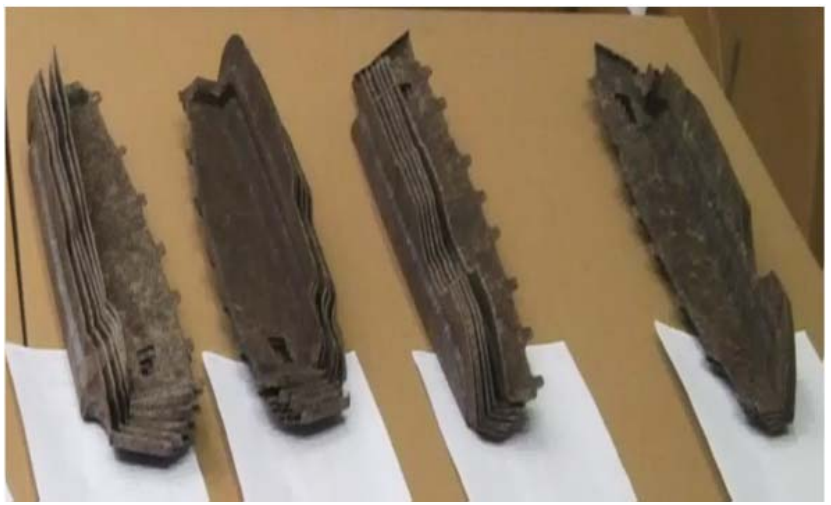

Figure 5. Armrest padding

A simple layout of the workplace was made for the purposes of the analysis which is shown in Figure 6. This layout is the basis for subtracting the actual dimensions and displaying the worker's movement within the Spaghetti diagram.

In the next step, it is necessary to define the individual activities of the worker resulting from the technological process and the existing work organization. For each activity, it is necessary to determine its duration and the number of repetitions within a fixed number of 50 production cycles, i.e. production of 200 pieces of products.

For this purpose, a video was taken and the analysis was performed using Assembly Operation Analysis [7], [8].

Figure 7 shows the print screen of the program. To the individual identified activities of the worker were added data about the number of repetitions in the production of 200 pieces of products.

These data allow us to analyze the movement based on a visual line-shaped display, calculate the actual travelled distance, and determine the production cycle time of 200 pieces of products. From the analysis it is clear that the main problem of this workplace is the handling of semi-finished products and subsequent storage of finished products in containers. This manipulation takes up a substantial part of the cycle time and is also labour intensive. 

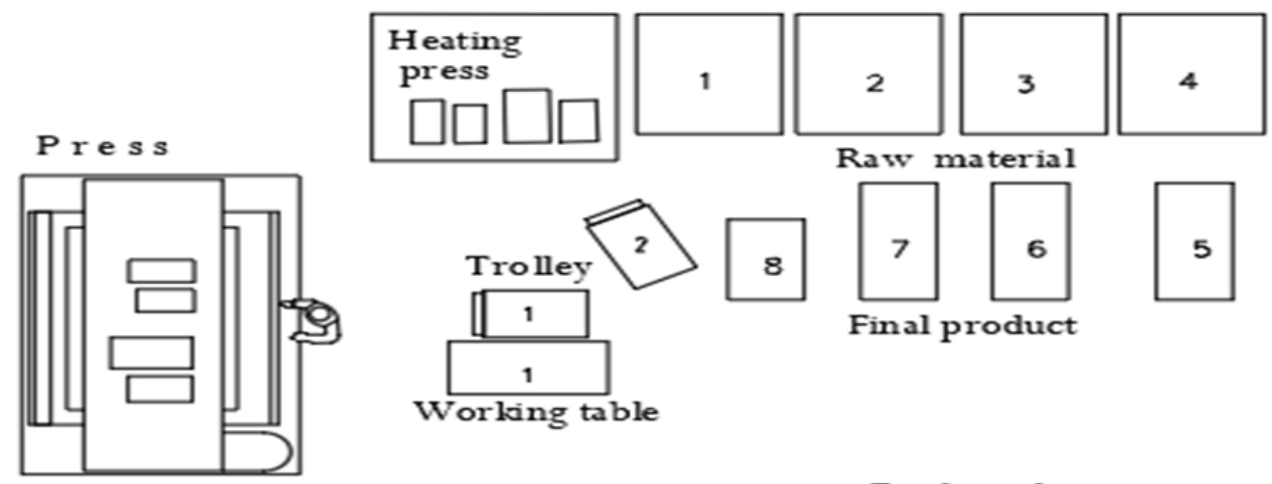

Final product

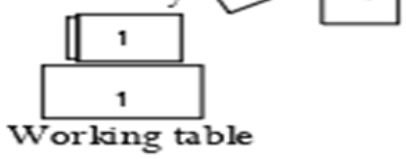

Final product

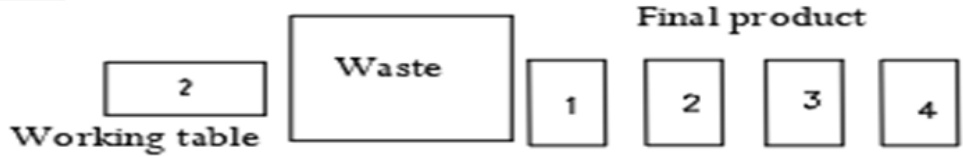

Figure 6. Layout of existing workplace

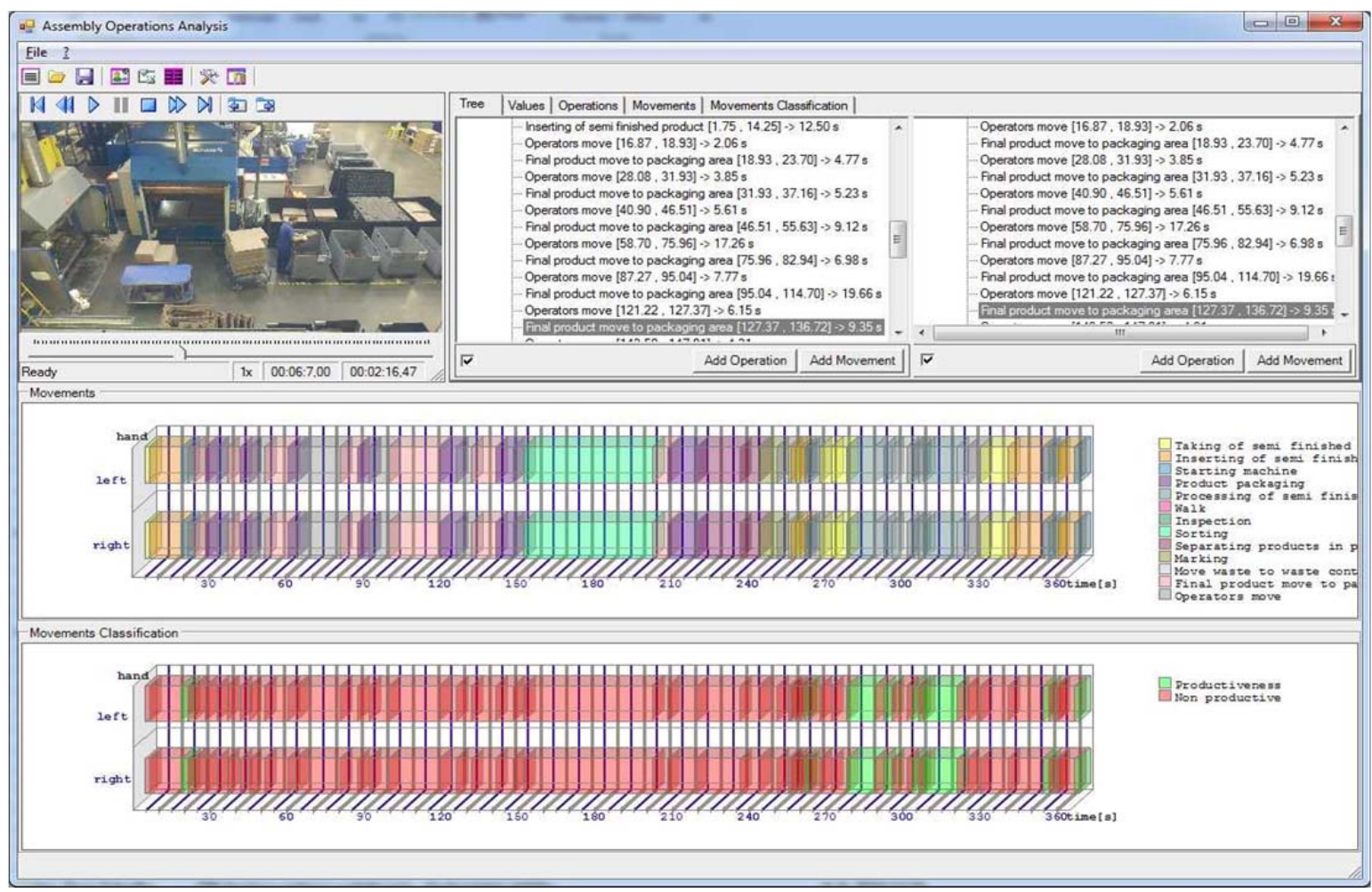

Figure 7. Print screen of the AOA-Assembly Operation Analysis program when analysing the time of individual activities in the existing workplace

\section{Spaghetti Diagram for Existing Production System}

According to the algorithm shown in Figure 1, it is possible to go to elaboration of the Spaghetti diagram. The procedure for using Excel application is published in detail. In the first step, the workplace layout was loaded into the diagram. Different image types, as well as formats, including hand sketch, can be used for analysis. It is important that the actual dimensions, i.e. $x$ and $y$ coordinate of all points, i.e. places, where the worker performs the activity or passes through.
This data will ensure that the calculated values will correspond to reality. Individual working points are color-coded. Red dots indicate workplaces; green dots are points through which a worker has to pass within a defined movement.

An activity repeat coefficient was used to create one complex Spaghetti diagram. In fact, it is possible to identify four basic different activities in the workplace (Table 1). Only activities that are not performed in each production operation are listed in this Table. The first variant contains all the activities and in this way 200 pieces of products are produced only once in a complex way. 
The second variant is performed only 2 times. The third option indicates a situation, where all other regular activities are performed. In the fourth variant, the insertion of the separating carton is not carried out, but only the insertion of the finished products into the container. Four types of work cycles are performed in the workplace.

Table 1. Basic variants of activities at the analysed workplace

\begin{tabular}{|c|c|c|c|c|c|}
\hline No. & Activity & $\begin{array}{c}\text { Variant } \\
1\end{array}$ & $\begin{array}{c}\text { Variant } \\
2\end{array}$ & $\begin{array}{c}\text { Variant } \\
3\end{array}$ & $\begin{array}{c}\text { Variant } \\
4\end{array}$ \\
\hline 1. & $\begin{array}{l}\text { Insertion of } \\
\text { semi-finished } \\
\text { product on } \\
\text { the trolley }\end{array}$ & $\mathbf{x}$ & & & \\
\hline 2. & $\begin{array}{l}\text { Insertion of } \\
\text { the } \\
\text { separating } \\
\text { carton }\end{array}$ & $\mathbf{x}$ & $\mathbf{x}$ & & \\
\hline 3. & $\begin{array}{l}\text { Movement to } \\
\text { the product } \\
\text { container }\end{array}$ & $\mathbf{x}$ & $\mathbf{x}$ & & $\mathbf{x}$ \\
\hline 4. & $\begin{array}{l}\text { Insertion of } \\
\text { the product } \\
\text { into the } \\
\text { product } \\
\text { container }\end{array}$ & $\mathbf{x}$ & $\mathbf{x}$ & & $\mathbf{x}$ \\
\hline
\end{tabular}

Figure 8 shows a complete Spaghetti diagram for the existing workplace. The red line shows the movement of the worker within the production area. It is also possible to see individual elements of Excel application such as the target, and target movement controls. Within the definition of the movement, it was necessary to enter 95 items in the program, along with 26 basis points (19 work positions and 7 transition points). At the same time, a basic classification of individual activities was proposed. The results of this classification are shown graphically in Figure 9.

In the graph, it can be seen that the activities of inserting the blanks into the heat press, removing the blanks from the heat press, inserting the blanks into the press, removing the finished products from the press and releasing the finished products i.e. removal of excess material are activities directly related to the production technology used.

The implemented lay-out changes do not allow a change in technology. This means that the time and distance values will not change at all or only minimally for these activities in the new designs.

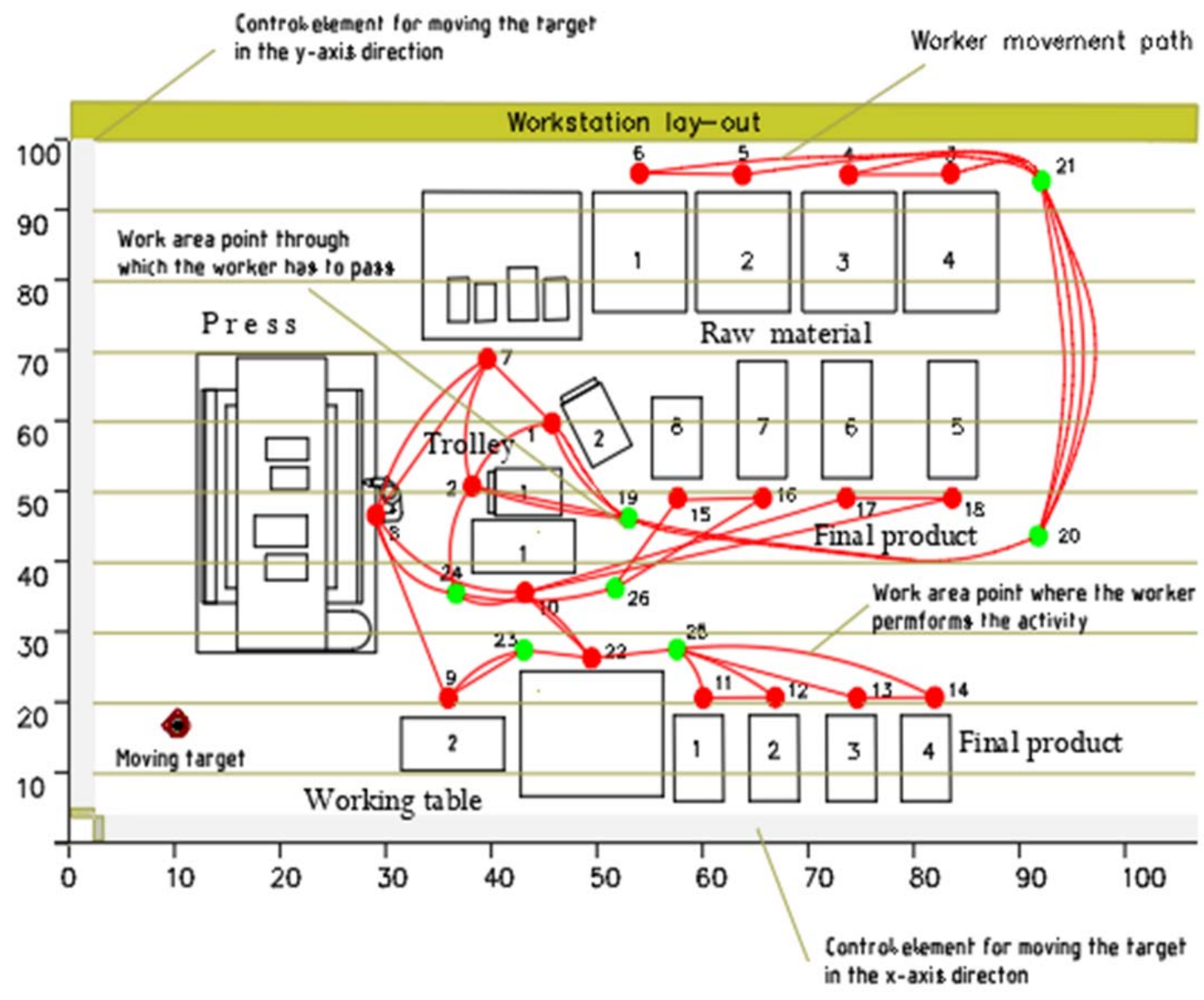

Figure 8. Spaghetti diagram for original workplace layout 


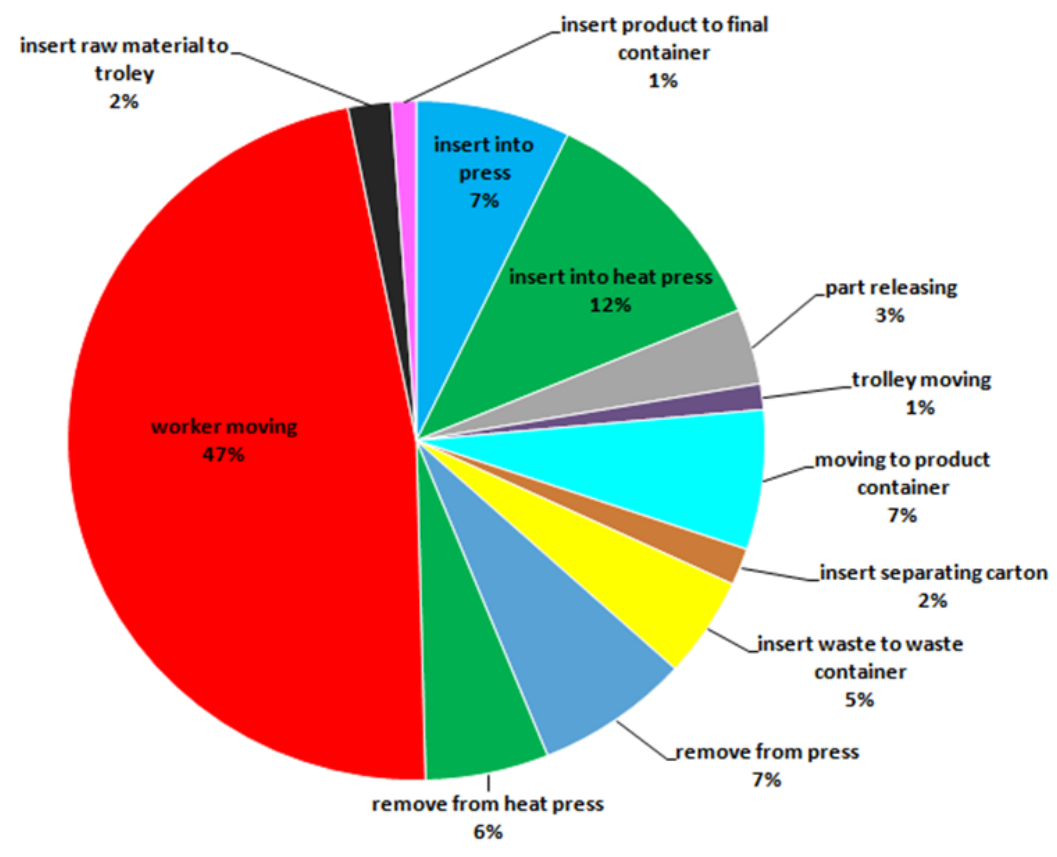

Figure 9. Classification of individual activities of the existing production system

The second group of activities is the insertion of a separating carton and the disposal of the waste after cleaning the finished products into the waste container, but these activities has little effect on the overall results.

In the third group are all other activities whose share in terms of time is $55 \%$. In terms of distance travelled, three activities (the movement of the worker, the movement of the trolley and the movement to the product containers) take up to $91 \%$. These activities can be influenced by changing the layout.

The result of the analysis is, in addition to the visual representation of the worker movement, also the total time of realized activities obtained from real data in the analyzed production system. Another result based on actual dimensional data is the distance travelled for a specified number of products.

The data are shown in Table 2. This existing data will be used in comparison with the results of the new layout variants. Together with other parameters such as the costs for implementation a layout change, they can serve as a basis for decision making.

Table 2. The resulting values of the layout analysis of the original workplace using the Spaghetti diagram

\begin{tabular}{|l|c|}
\hline Parameter & Original lay-out \\
\hline Time performance of activities & 116,46 min. \\
\hline Distance traveled & 2822,3 meters \\
\hline Number of products & 200 pieces \\
\hline
\end{tabular}

\section{Proposed Changes in the Workplace Layout}

In this process (proposal of layout changes of the workplace), which is shown in Figure 10, all restrictions were taken into account. The constraint was that it was not possible to change the position of the heating press and the press. Furthermore, it was not possible to change the production technology itself, the size and the number of containers of semifinished products, final products and the waste container.

In the first proposal variant, the trolleys for semifinished products were kept and one trolley for transport of the finished products to the containers for the finished products was added. This solution allows reducing the number of worker movements to the product containers.

By repositioning the containers, access to the stock containers has been allowed, and this action shortens the movement of the trolley 1 and the trolley 2. By moving the workbenches the space in front of the press became free and the movement within the workstation is smoother and more straightforward.

The second variant of the layout change (Figure 11) contains only one workbench designed to release the finished product. The released products gradually accumulate on a trolley 2, which is larger than the trolley in variant 1 and on which it is possible to gradually store the finished products.

For the handling with the semi-finished products, it is also used the trolley with dimensions which allow all semi-finished products transport to the heating press. This will reduce the distance travelled by the worker when supplying the workplace. The expected movement of the worker will also be more straightforward than at the original workplace. In both new proposals, there is enough space for handling with containers. Their number and dimensions did not change either. 


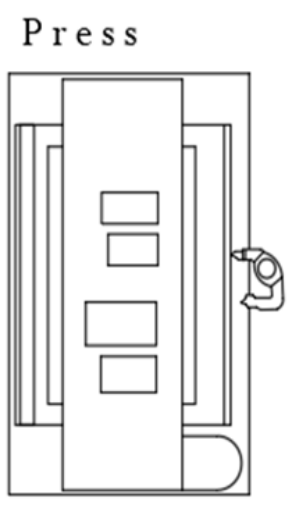

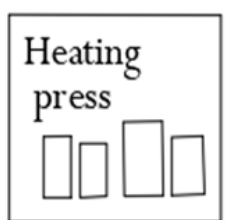

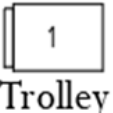

3.

Trolley

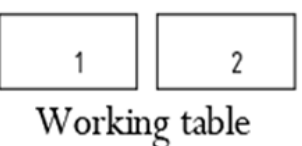

Working table

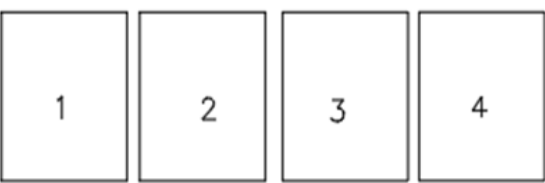

Raw material

2

Trolley

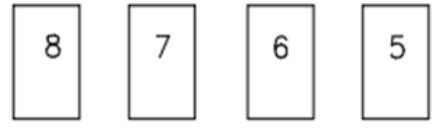

Final product

Figure 10. First variant of workplace layout change

Press

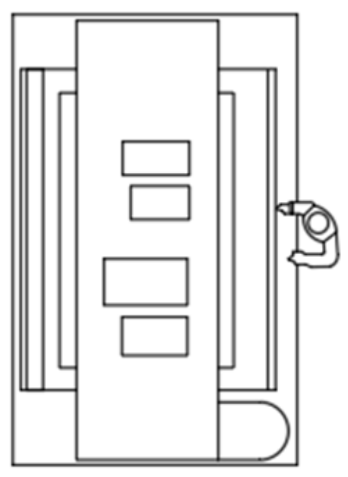

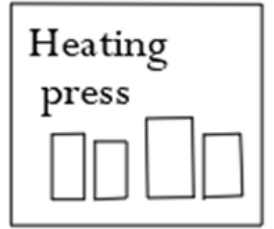

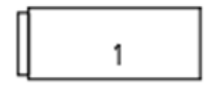

Trolley
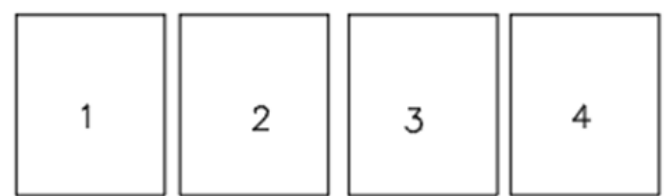

Raw material
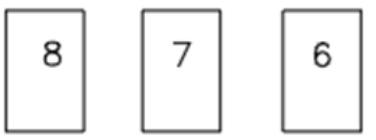

5

Final product
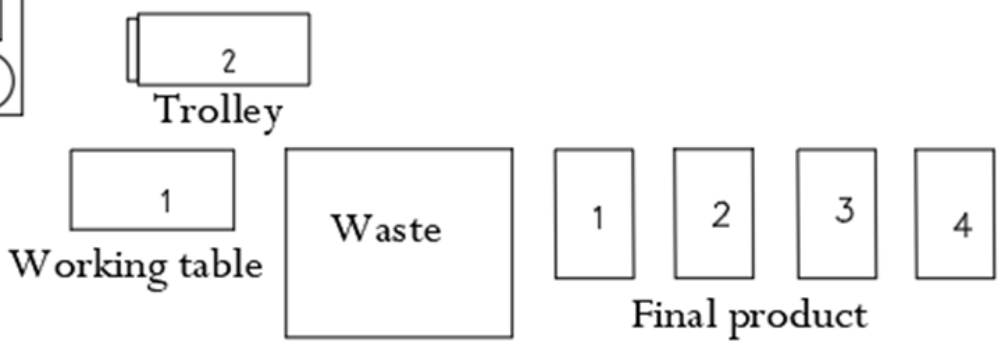

Final product

Figure 11. Second variant of workplace layout change

\section{Spaghetti Diagrams for New Layout Variants}

In a similar way to the existing workplace layout, Spaghetti diagrams of new proposals were created in Excel application. Figure 12 is a print screen with Spaghetti diagram. In this proposal, 20 work positions have been identified and the diagram itself in the data entry section about movement contains 69 items. The worker movement is smoother than in the original layout.

The Spaghetti diagram of the second layout change proposal shown in Figure 13 contains 19 work positions and 64 items were required to enter movement data. In both new proposals, there was no necessity to use so called transition points that are used in the Spaghetti diagram of the existing layout and are shown in green (see Figure 8).

After entering the movement, time data and the number of repetitions of each activity were entered to calculate the results.

The production technology itself as well as the operation of both production facilities remained unchanged and the operating time data are the same as in the existing layout. 


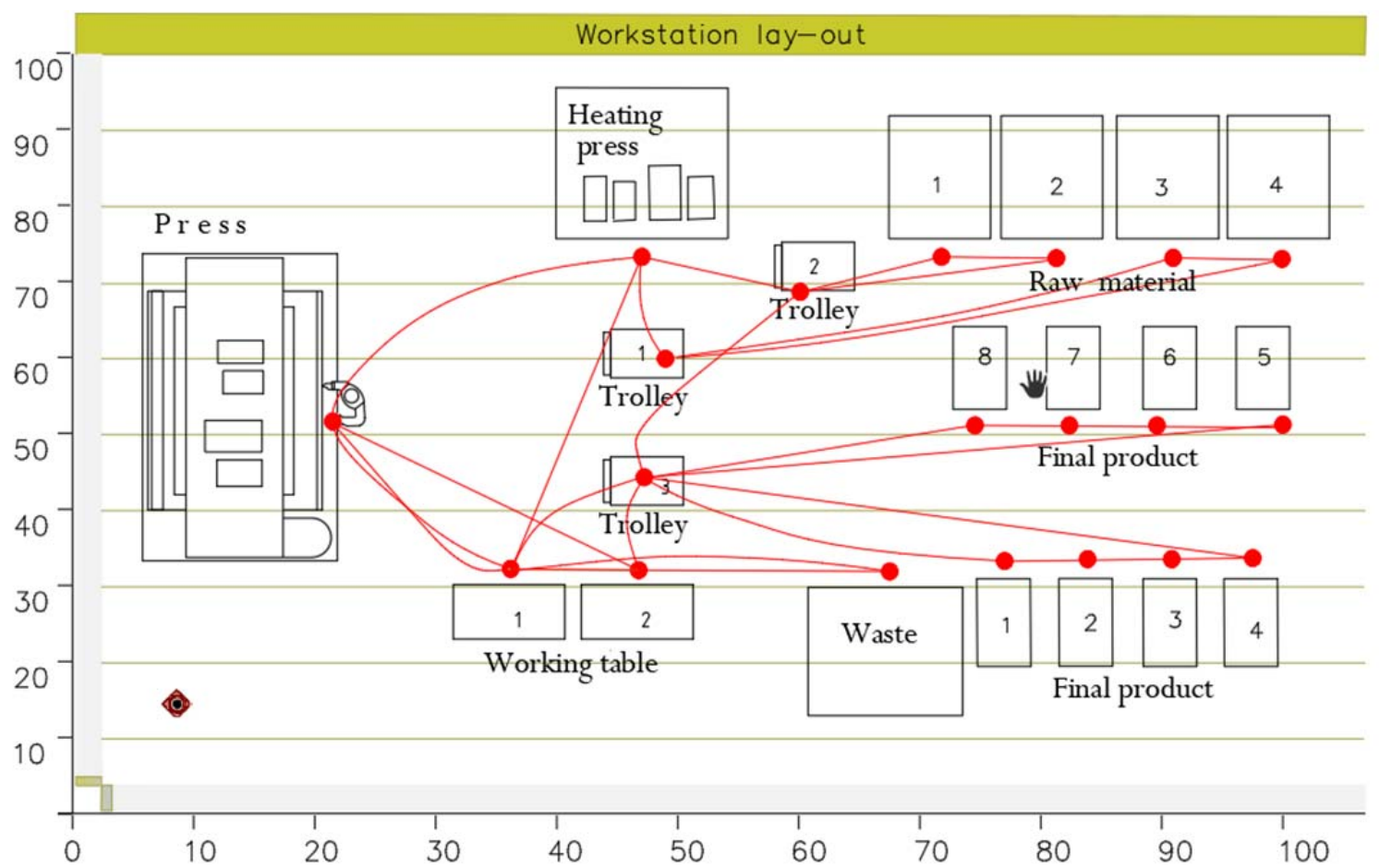

Figure 12. Spaghetti diagram for the first variant of workplace layout change

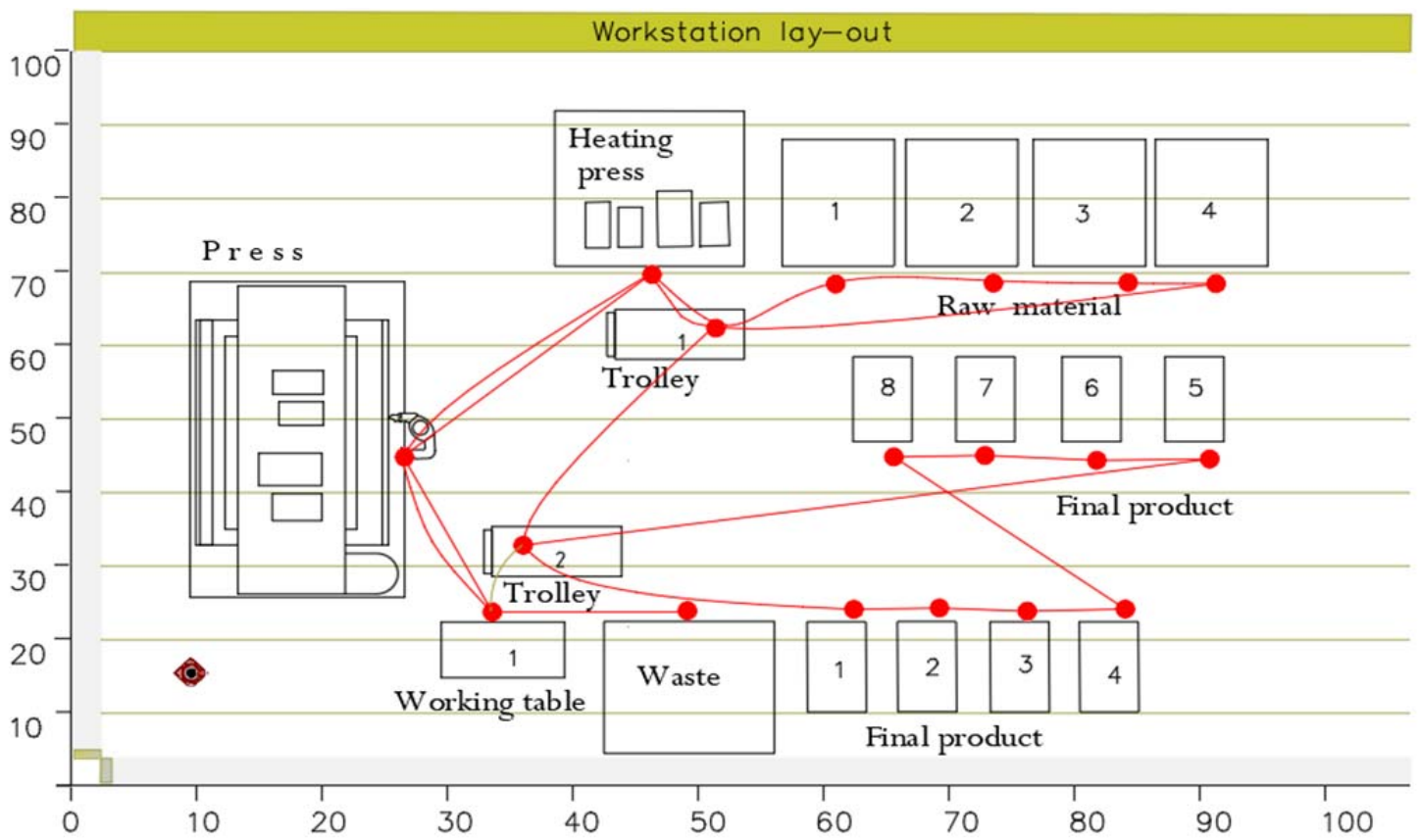

Figure 13. Spaghetti diagram for the second variant of workplace layout change

\section{Comparison of Analysis Results}

Spaghetti diagram (Excel application) allows us to compare the results of the analysis of each variant. The basic results are the time performance of the activities and the distance travelled. In the present case are these summary data for 50 technological operations, i.e. 200 products. In Table 3 are summarized the results including the recalculated number of products per day and the distance travelled per day.
Table 3. Layout variants and their parameters

\begin{tabular}{|c|c|c|c|}
\hline Parameter & $\begin{array}{c}\text { Original } \\
\text { (existing) } \\
\text { layout }\end{array}$ & $\begin{array}{c}\text { Layout } \\
\text { change 1 }\end{array}$ & $\begin{array}{c}\text { Layout } \\
\text { change 2 }\end{array}$ \\
\hline $\begin{array}{c}\text { Time performance } \\
\text { of the activities } \\
\text { for 200 products }\end{array}$ & $\begin{array}{c}116,46 \\
\text { minutes }\end{array}$ & $\begin{array}{c}105,34 \\
\text { minutes }\end{array}$ & $\begin{array}{c}95,67 \\
\text { minutes }\end{array}$ \\
\hline $\begin{array}{c}\text { Distance traveled } \\
\text { for 200 products }\end{array}$ & $\begin{array}{c}2822,3 \\
\text { meters }\end{array}$ & $\begin{array}{c}2403,9 \\
\text { meters }\end{array}$ & $\begin{array}{c}2032,1 \\
\text { meters }\end{array}$ \\
\hline $\begin{array}{c}\text { Number of } \\
\text { products per day }\end{array}$ & 772 pieces & $\begin{array}{c}854 \\
\text { pieces }\end{array}$ & 940 pieces \\
\hline $\begin{array}{c}\text { Distance traveled } \\
\text { per day }\end{array}$ & $\begin{array}{c}10905,2 \\
\text { meters }\end{array}$ & $\begin{array}{c}10269,2 \\
\text { meters }\end{array}$ & $\begin{array}{c}9558,3 \\
\text { meters }\end{array}$ \\
\hline
\end{tabular}


In Figure 14 are graphs of comparison of three layout variants according to number of produced products per day and distance travelled.

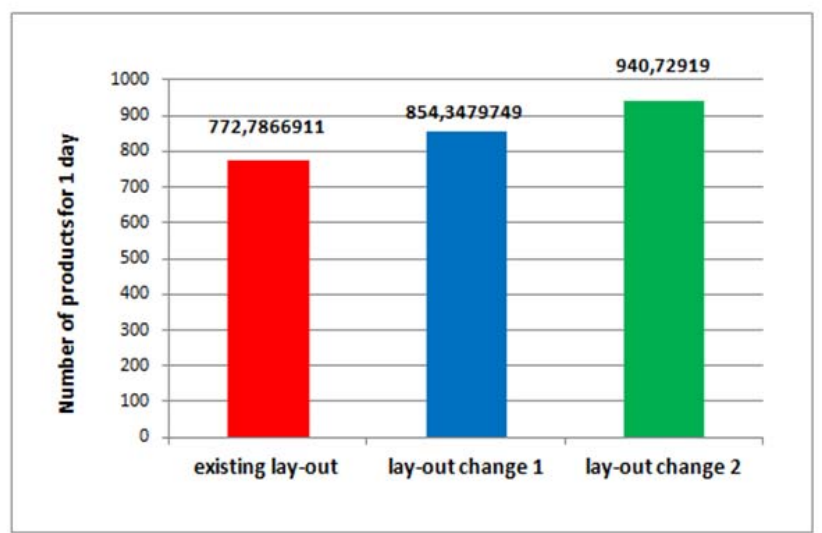

It should be stated that the data in the graphs are calculated and do not take into account scraps, different types of downtimes and failures.

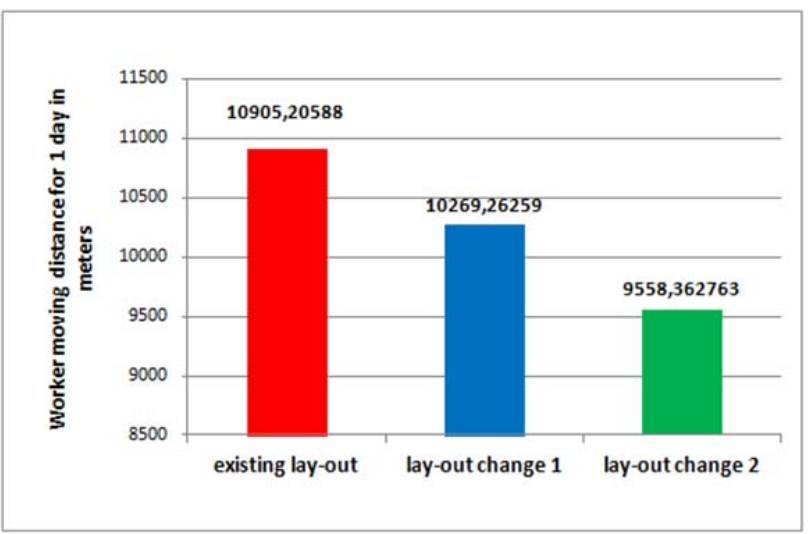

Figure 14. Output of variants comparison in the form of graph - number of products per day - left and distance traveled by worker per day - right

The most advantageous variant is the second layout change proposal, which uses two larger trolleys and only one workbench. This makes it possible to reduce the time and movement of the worker towards the containers with semi-finished and finished products. The solution also requires relocation of the containers while respecting the access requirement for their replacement.

In general, it is necessary to agree the exact extent of the layout change process; i.e. set the boundaries of the problem. In the presented case, for example, it was not possible to change the containers, i.e. deal with transport of containers, their storage and expedition. It was also not possible to deal with the issue of preparation - cutting of semi-finished products and, for example, to include this process into the existing workplace.

Another aspect in the proposal process was to agree the elements that are fixed and therefore cannot be changed. These elements were the number of workers, the location of the machines, the available work area and the production technology. If, for example, one of the above-mentioned items could be changed, layout change would be more efficient in terms of saving time and distance travelled.

By changing the layout without intervention in the production technology, product design, increasing the degree of automation, etc. savings in small percent are possible.

\section{Conclusion}

Spaghetti diagram is one of the tools of Lean production [6]. The Excel application has been created to increase its efficiency. Its usage is effective for evaluation of the selected parameters time and distance of layout or more layouts. It is important, that reliable input data, detailed knowledge of the production process and appropriate classification of individual movements, have to be available. It takes about 90 minutes to elaborate a Spaghetti diagram for about 50-60 items. In the case of a higher number of items, the time increases accordingly.

The Excel application that we used is the most effective for layouts with about 20 work positions, i.e. for individual workplaces with less technical equipment. In the case of large production clusters, this application can also be used, but due to the size of the image that can be loaded as well as the fact that the input data are shown in the form of a table, it may be more time consuming to elaborate and check the correctness of data. Of course, the spaghetti diagram is only one of the possibilities to evaluate layout [9], [11]. Another possible method is, for example, a transport matrix. Of course, other important solution parameters have to also be taken into account when deciding which of the proposed variants will be implemented. 


\section{Acknowledgement}

This work has been supported by the Scientific Grant Agency of the Ministry of Education of the Slovak Republic (Project KEGA 032EU-4/2020 a KEGA 002TUKE-4/2020).

\section{References}

[1]. Allen, T. T. (2010). Introduction to Engineering Statistics and Lean Sigma: Statistical Quality Control and Design of Experiments and Systems. Springer Science \& Business Media.

[2]. Di Pietro, L., Mugion, R. G., \& Renzi, M. F. (2013). An integrated approach between Lean and customer feedback tools: An empirical study in the public sector. Total Quality Management \& Business Excellence, 24(7-8), 899-917.

[3]. Drábik, P., Rehák, R., Vernerová, D., \& Kukura, M. (2020). Rational Consumer in the Context of Environmental Protection 1. Ekonomicky Casopis, 68(10), 1081-1104.

[4]. Gladysz, B., Santarek, K., \& Lysiak, C. (2017, September). Dynamic spaghetti diagrams. A case study of pilot RTLS implementation. In International Conference on Intelligent Systems in Production Engineering and Maintenance (pp. 238-248). Springer, Cham.

[5]. Hys, K., \& Domagała, A. (2018). Application of spaghetti chart for production process streamlining. Case study. Archives of Materials Science and Engineering, 89(2), 64-71.

[6]. Jurova, M., Korab, V., Videcka, Z., Jurica, P., \& Bartosek, V. (2016). Manufacturing and logistics processes in business. Praha: FINIDR.
[7]. Kanaganayagam, K., Muthuswamy, S., \& Damodaran, P. (2015). Lean methodologies to improve assembly line efficiency: An industrial application. International Journal of Industrial and Systems Engineering, 20(1), 104-116.

[8]. Lingayat, S. S., Vasani, R. S., Kulkarni, G., Ambhore, S. S., Sharma, S., \& Rautela, L. D. (2015, February). Optimization of product, tool \& process design concept through SMED technique. In 2015 International Conference on Technologies for Sustainable Development (ICTSD) (pp. 1-6). IEEE.

[9]. Sharma, P., \& Singhal, S. (2016). Design and evaluation of layout alternatives to enhance the performance of industry. Opsearch, 53(4), 741-760.

[10]. Raikar, N. A., Kattimani, P., \& Walke, G. (2015). Use of Spaghetti Diagram for Identification and Elimination of Waste Movements in Shop Floor for OEE Improvement: A Case Study. International Journal of Engineering Research \& Technology, 4(5), 1145-1149.

[11]. Sayer, N. J., \& Williams, B. (2012). Lean for dummies. John Wiley \& Sons.

[12]. Senderská, K., Mareš, A., \& Václav, Š. (2017). Spaghetti diagram application for workers' movement analysis. UPB Scientific Bulletin, Series D, 79(1), 139-150.

[13]. Sugandhi, S. D., \& Bharule, A. (2016). Fine Blanking Plant Layout Improvement Using Systematic Layout Planning. International Journal of Scientific Engineering and Research (IJSER), 4(4), 14.

[14]. Wilson, L. (2010). How to implement lean manufacturing. McGraw-Hill Education.

[15]. Womack, J. P., \& Jones, D. T. (1997). Lean thinking - banish waste and create wealth in your corporation. Journal of the Operational Research Society, 48(11), 1148-1148. 